\title{
Effects of Changing Rainfall and Soil Temperature on Population Density of Pratylenchus loosi in Tea Lands at Different Elevations
}

\author{
P.G.D.S. Amarasena ${ }^{*}$ K.M. Mohotti and D.M. De Costa ${ }^{1}$ \\ Postgraduate Institute of Agriculture \\ University of Peradeniya \\ Sri Lanka
}

\begin{abstract}
The climatic, elevational and edaphic factors are the major abiotic determinants of survival and reproductive behavior of plant pathogenic nematodes and thus responsible for their occurrence, population levels and severity of symptom development. Present study attempted to determine relationship between rainfall, soil temperature and soil moisture on soil and root population densities of Pratylenchus loosi, the key nematode pest of tea in six different elevation regimes in Sri Lanka. Rainfall, soil temperature and soil moisture of six locations were recorded by standard methods over 18 months. $\underline{P}$. loosi populations in soil and root samples obtained from the same locations were also monitored using standard methods. The fluctuating nematode population density was correlated with rainfall, soil temperature and soil moisture. There was a positive correlation of $\underline{P}$. loosi population density with mean rainfall and negative correlation with soil temperature and soil moisture content in majority of the tested locations. Results also revealed an increase in mean soil temperature above the optimal range for development of $\underline{P}$. loosi and a remarkable change in soil temperature range of $18-24^{\circ} \mathrm{C}$. However, there were exceptions in some locations indicating that factors other than temperature have influenced nematode population. Nevertheless, presence of $\underline{P}$. loosi at increased soil temperature ranges beyond the acceptable range was evident in certain locations making disease expressions and damage to tea. Therefore, further investigations are warranted on the presence of new biotypes and the influence of other factors for development of $\underline{P}$. loosi population in view of developing specific management strategies.
\end{abstract}

Keywords: Rainfall, root and soil nematode population, soil temperature, soil moisture content

\section{INTRODUCTION}

Tea, Camellia sinensis (L) O. Kunze (Theaceae) is the major plantation crop grown in Sri Lanka. With its wide adaptability, tea is grown in a range of climates and soils in different agro ecological regions (AERs). Productivity of tea depends on various environmental and biological factors irrespective of the cultivar grown. The crop and soil management practices adopted, changing weather conditions and pest and disease incidences also determine the overall crop productivity.

\footnotetext{
1 Department of Agricultural Biology, Faculty of Agriculture, University of Peradeniya, Peradeniya

Corresponding author: deepthiamarasena@yahoo.com
} 
Plant parasitic nematodes are considered as one of the key pests which limits the establishment, growth and productivity of tea. Pratylenchus loosi is the most predominant nematode species causing economic damage to tea cultivation in Sri Lanka as well as many of other tea growing countries such as Japan, Iran, Bangladesh, China, and Korea. It is a perennial pest attacking both young and old plants and thus a problem in tea nurseries, new clearings as well as in mature tea fields (Gnanapragasam and Mohotti, 2008). In Sri Lanka, the damage of $P$. loosi to tea crop has been estimated to be in the range of $4 \%$ to $40 \%$ (Gnanapragasam and Mohotti, 2005).

Nematodes are among the most sensitive animals in aquatic and soil ecosystems. Changes in soil temperature and moisture as affected by rainfall, sunshine hours, number of wet and dry days with climate change influence on the biology, morphology, locomotion, multiplication, establishment and survival of plant pathogenic nematode species (Liliane et al., 1999). Studies have demonstrated that geographical distribution range of plant and animal parasitic nematodes and their spread to newer areas may get expanded with global warming (Somashekar et al., 2010).

The severity of damage by nematodes to tea depends on the interaction of number of factors such as prevailing climatic conditions, type of soil, cultural practices and age and vigor of the plant (Gnanapragasam, 1994). The distribution of $P$. loosi is determined mainly by soil temperature and soil moisture (Gnanapragasam and Mohotti, 2005). Sivapalan and Gnanapragasam (1975) reported that highest population and obvious pathogenicity symptoms of $P$. loosi had been encountered at altitudes with soil temperatures of $18-24{ }^{\circ} \mathrm{C}$. Sivapalan (1972) also experienced less rate of population build-up of $P$. loosi and consequently reduced damage to tea at temperatures above and below the ambient temperature range. Further, a marked periodic fluctuation of $P$. loosi population levels has been observed in different months of the year where the variation was correlated to rainfall pattern and soil temperature (Sivapalan, 1972). In addition, Mohotti (2009) reported a significant shift in nematode populations and their distribution patterns with probable elevation of soil temperatures in respective tea growing regions, which was supported by evidences of Wijeratne (2013) on clear changes in weather parameters in all tea growing regions. Although $P$. loosi has been designated as an 'Up Country species of nematodes', in the recent past, it is reported in mid and low elevations of Sri Lanka. Nevertheless, P. loosi behaves as a species complex as reported in Sri Lanka, Japan and Iran (Mizukubo, 1998; Mohotti, 1998) the reasons for which have not been elucidated clearly as weather, host plants, cultural practices etc. Though, climate change impacts have been attributed for alterations in morphological, morphometric and molecular expressions of animal and plants, studies on nematodes are scanty. Hahn et al. (1994) reported the R. similis races / pathotypes in Sri Lanka based in relation to host status and localities. However, no descriptive studies have been conducted on $P$. loosi.

These findings underline the importance of understanding the impact of climate change on soil nematodes and its implications to agricultural systems while developing mitigation and adaptation strategies to address the impact of climate change on agriculture. More importantly, the present evidences on unusual existence and spread of $P$. loosi and its remarkable damage to tea in Sri Lanka warrant urgent interventions in managing the pest, Therefore, the present study was conducted to determine the effects of rainfall, soil temperature and soil moisture on population densities of $P$. loosi in tea lands at different elevation regimes together with the correlations of each climatic parameter on the nematode density. 


\section{METHODOLOGY}

\section{Selection of sampling sites}

Sampling sites were selected by reviewing past records of $P$. loosi infestations in tea lands maintained by the Nematology Laboratory of the Tea Research Institute. Accordingly, Cicilton Estate, Hapugastenna Estate, Mahadowa Estate, Richiland Estate, Delmar Estate and a small holder land at Nawalapitiya were selected representing different elevations and soil temperature regimes (Table 1).

Table 1. Details of the sampling sites

\begin{tabular}{|c|c|c|c|c|c|}
\hline $\begin{array}{l}\text { Code } \\
\text { No. }\end{array}$ & Location & Latitude & Altitude & AER & $\begin{array}{c}\text { Elevation } \\
(\text { amsl in } \mathrm{m})\end{array}$ \\
\hline PL1 & Cicilton Estate & $6^{0} 43^{\prime} 60^{\prime \prime} \mathrm{N}$ & $80^{0} 39^{\prime} 0$ '” & IM2b & 780 \\
\hline PL2 & Delmar Estate & $7^{0} 00^{\prime} ’ \mathrm{~N}$ & $80^{0} 52^{\prime} 0^{\prime \prime} \mathrm{E}$ & IU2 & 1400 \\
\hline PL3 & Hapugastenna Estate & $6^{0} 69^{\prime} 3 ” \mathrm{~N}$ & $80^{0} 38^{\prime} 6^{\prime \prime} \mathrm{E}$ & WM1a & 810 \\
\hline PL4 & Mahadowa Estate & $7^{0} 0^{\prime} 0^{\prime \prime} \mathrm{N}$ & $81^{0} 10^{\prime} 0$ ”'E & $\mathrm{IU} 3 \mathrm{c}$ & 1280 \\
\hline PL5 & $\begin{array}{l}\text { Nawalapitiya (Small } \\
\text { holder land) }\end{array}$ & $7^{0} 3^{\prime} 0{ }^{\prime \prime} \mathrm{N}$ & $80^{0} 32^{\prime} 0^{\prime \prime} \mathrm{E}$ & WM2a & 550 \\
\hline PL6 & Richiland Estate & $6^{0} 19^{\prime} 28^{\prime \prime} \mathrm{N}$ & $80^{0} 33^{\prime} 43^{\prime \prime} \mathrm{E}$ & WM1a & 230 \\
\hline
\end{tabular}

Soil and root samples were collected from the six selected sampling sites during the period of February 2014 - May 2015 to assess nematode populations at monthly intervals. About 10-15 samples were collected from each location and about $50 \mathrm{~g}$ soil was collected from each sampling point. The samples were taken $15 \mathrm{~cm}$ away from the base of the bush and at a depth of $15-25 \mathrm{~cm}$ with an auger. Samples were pooled and about $500 \mathrm{~g}$ of the composite soil sample was prepared. The root samples each containing $5 \mathrm{~g}$ feeder roots were collected from the same sampling points along with the soil samples. The composite samples were brought to the laboratory for nematode estimation.

\section{Collection of Weather Data}

Soil temperature data were collected on daily basis, twice a day at $8.30 \mathrm{am}$ and $3.30 \mathrm{pm}$ at a depth of $10 \mathrm{~cm}$ using soil thermometers. Rainfall data were collected on daily basis during the experimental period using rain gauges established in respective locations.

\section{Determination of Soil Moisture Content}

Soil moisture content was determined at the time of sampling at monthly intervals. Oven dry method was used for determination of soil moisture content. About $100 \mathrm{~g}$ soil was taken into a moisture can and kept at $105^{\circ} \mathrm{C}$ overnight.

\section{Extraction and quantification of nematodes}

Soil and root samples were processed for extraction of nematodes using modified Baermann Funnel Technique and Whitehead tray method, respectively (Southey, 1986). Processed samples were observed under light microscope and $P$. loosi counts were taken. Identification of the species $P$. loosi was done as per the morphological parameters. Data on P. loosi counts per $100 \mathrm{~g}$ soil and $5 \mathrm{~g}$ roots were taken separately. 


\section{Data Analysis}

The soil temperature, rainfall and soil moisture data were analyzed using Statistical Application Software (SAS) 9.1. Correlations between weather data and soil and root populations of $P$. loosi at six locations monitored over 18 months were performed using correlation analysis.

\section{RESULTS AND DISCUSSION}

Data on rainfall, soil temperature and soil moisture monitored in six locations (i.e. PL1-PL6) over the experimental period in order to determine the variation of parameters attributable for changes of nematode behavior, population densities and resultant disease expressions are presented in Table 2 .

Table 2. Rainfall, soil temperature and soil moisture data of the study locations PL1PL6

\begin{tabular}{|c|c|c|c|c|c|c|c|c|}
\hline \multirow{3}{*}{ Location } & \multirow{2}{*}{\multicolumn{2}{|c|}{ Rainfall (mm) }} & \multicolumn{4}{|c|}{ Soil Temperature $\left({ }^{0} \mathrm{C}\right)$} & \multirow{2}{*}{\multicolumn{2}{|c|}{ Soil Moisture $\left({ }^{\%}\right)$}} \\
\hline & & & $\mathbf{A M}$ & & $\mathbf{P M}$ & & & \\
\hline & Range & Mean & Range & Mean & Range & Mean & Range & Mean \\
\hline PL 1 & $1.2-23.0$ & 11.19 & $19.47-21.38$ & 20.97 & $20.97-25.68$ & 24.31 & $12.0-20.0$ & 14.64 \\
\hline PL 2 & $0.36-18.3$ & 4.91 & $16.4-20.5$ & 18.33 & $19.3-30.9$ & 26.0 & $6.00-7.1$ & 6.80 \\
\hline PL 3 & $5.49-39.47$ & 18.50 & $21.8-23.7$ & 22.90 & $23.5-25.2$ & 24.6 & $15.6-29.3$ & 23.3 \\
\hline PL 4 & $0.73-14.28$ & 6.02 & $18.4-26.1$ & 20.18 & $23.57-23.97$ & 24.44 & $17.8-23.6$ & 19.76 \\
\hline PL 5 & $0.0-35.08$ & 8.79 & $22-23.19$ & 22.68 & $23.42-24.45$ & 24.13 & $22.9-31.8$ & 27.56 \\
\hline PL 6 & $0.0-27.23$ & 13.70 & $24.90-27.0$ & 25.80 & $28.8-31.2$ & 30.0 & $21.8-31.8$ & 26.1 \\
\hline
\end{tabular}

As presented in Table 2, a wide variation of rainfall, soil temperature and soil moisture, among locations and within a given location was observed. The highest mean values for rainfall, soil temperature (a.m.), soil temperature (p.m.) and soil moisture were reported from PL3, PL6, PL6 and PL5 locations respectively. In contrast, the lowest mean values for the above parameters were reported respectively from the PL2, PL2, PL5 and PL2 locations. Such changes would probably influence behavior, life cycle and population dynamics of $P$. loosi in any given location which would resultantly interfere in differences in disease expressions exhibited as symptoms as well as adaptations of $P$. loosi. Therefore, in order to understand the impacts of the changed weather parameters on nematode population densities, data were correlated.

\section{Correlation between soil population of $P$. loosi and Soil Temperature}

Soil temperature determines most of biological factors of living organisms where plant parasitic nematodes are no exception. Moreover, soil temperature has been identified as the most determining factor for $P$. loosi incidence in tea (Sivapalan and Gnanapragasam, 1975). The optimal soil temperature range for $P$. loosi was determined as $18-24{ }^{\circ} \mathrm{C}$ favored through a well distributed rainfall. However, results of the present study on data collected over a period of 18 months in six locations revealed an increase in mean soil temperature above the optimal range for development of $P$. loosi (Fig. 1), Soil temperatures in PL 2 and PL6 locations were beyond $24^{\circ} \mathrm{C}$. Unusually, a remarkable change in soil temperature ranges was also seen in most locations except in PL2. The highest and lowest men soil temperatures were recorded from PL6 and PL2 locations respectively. The difference of soil temperature 
on P. loosi population was insignificant between the other locations (PL 1, PL 3, PL 4 and PL 5). A negative correlation between soil temperature and $P$. loosi population in soil was evident in locations except in PL $1\left(\mathrm{R}^{2}=0.006\right)$ and PL $4\left(\mathrm{R}^{2}=0.173\right)$ (Fig. 1).

Though the highest $P$. loosi populations have been encountered at altitudes with soil temperatures of 18-24 ${ }^{\circ} \mathrm{C}$ as reported by Sivapalan and Gnanapragasam (1975), our results support the presence of $P$. loosi populations at locations above the optimum range. They are also in par with the results of Mohotti (2009) on the remarkable shift in P. loosi populations in the different agro-ecological regions. As such, the populations may behave as different isolates and express individual disease symptoms. Other factors responsible in population fluctuation of $P$. loosi however, need to be elucidated.

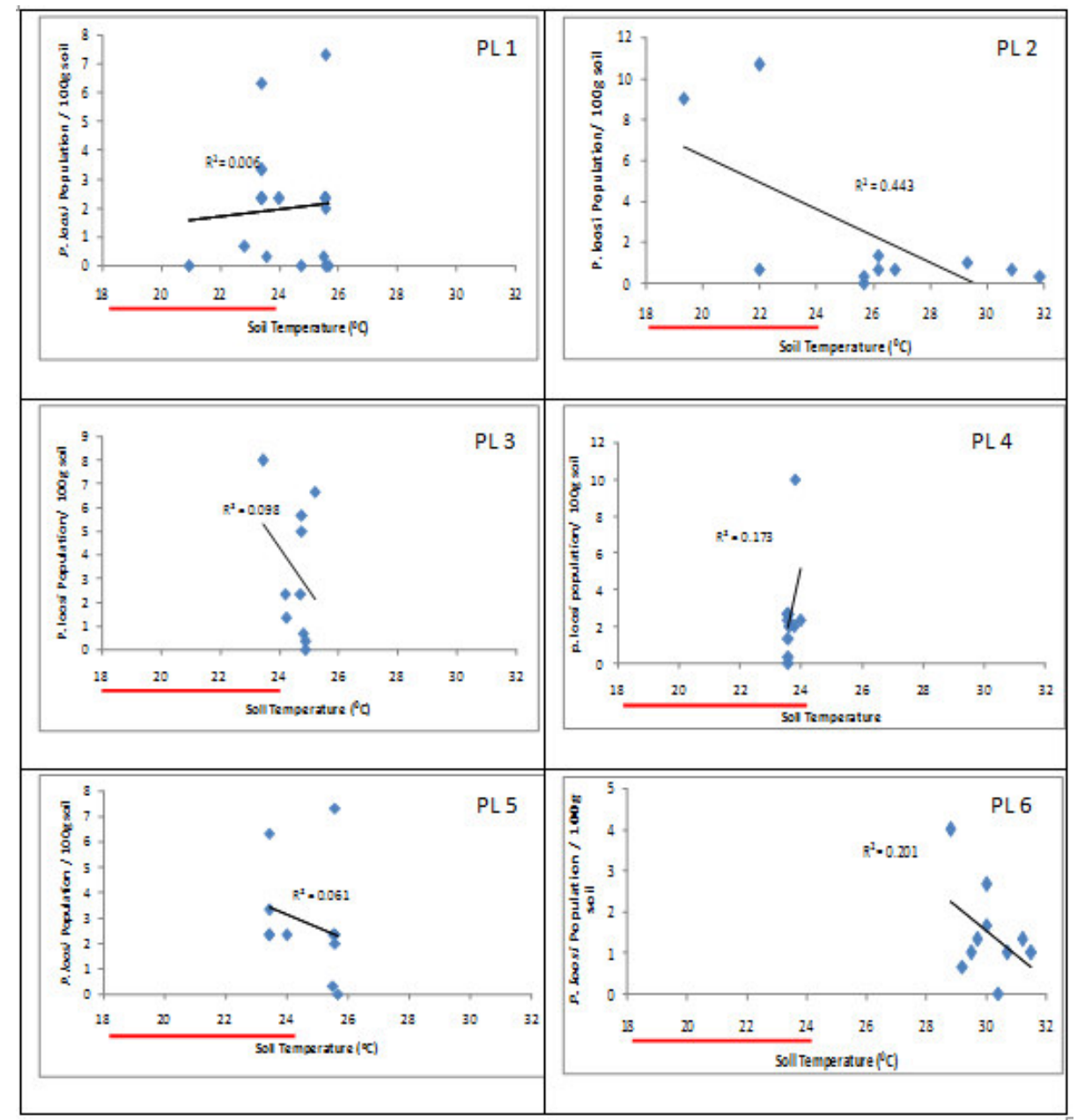

Fig 1. Correlation between Soil Temperature and $P$. loosi population densities in soil in Locations PL1 -PL6 (Red line indicates the optimal soil temperature range preferable for $P$. loosi: $18-24^{0} \mathrm{C}$ )

The results of the present study also validate potentials of wide spreading of $P$. loosi species and its dominating ability in all tea growing regions. It also shows concomitant occurrence of 
$P$. loosi with other nematode species such as $R$. similis requiring higher soil temperatures. In contrast, $R$. similis has been sensitive with such climate change scenarios as its occurrence has been minimized in general and in certain locations previously known as critical, has been totally replaced by $P$. loosi (Mohotti, 2009). Hence, P. loosi showed its virulence as a dominating nematode species with potential survival mechanisms and adaptations to get established and developed even under extreme weather conditions. This warrants further understanding as well as search for novel management practices.

\section{Fluctuation of soil population of $P$. loosi as Influenced by the Mean Rainfall}

P. loosi densities fluctuate with mean rainfall at different locations (Fig. 2). In PL2 and PL6 locations, very low nematode densities $(<2$ nematodes $/ 100 \mathrm{~g}$ of soil) were recorded during the experimental period despite PL6 had a reasonably well-distributed rainfall.

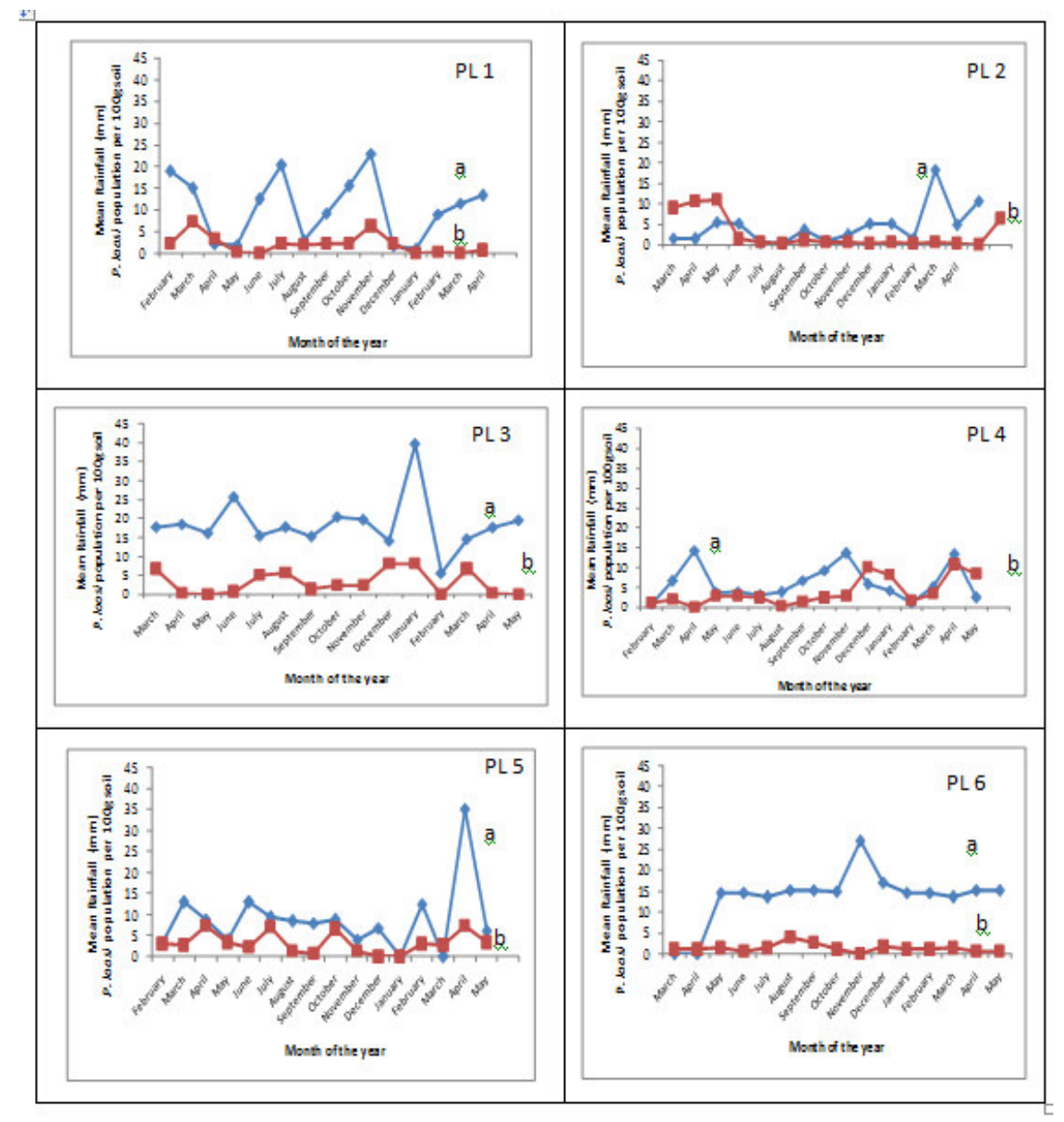

Fig 2. Mean rainfall during the experimental period (a) and the fluctuation of $P$. loosi densities (nematodes/100 g of soil) in soil (b) in locations PL1-PL6.

The initial understanding by Hutchinson and Vythilingam (1963) was that large populations of $P$. loosi being encountered in areas with high and well distributed rainfall. P. loosi has 
also been found abundantly in tea growing areas experiencing south-west monsoon rains than those having north-east monsoon rains (Hutchinson and Vythilingam, 1963). And, results of our study do support except in locations of PL2 and PL6.

This indicates that rainfall is not the only environmental factor determining $P$. loosi density in tea soils. Effects of altitude, soil temperature, soil texture have also been reported to play a significant role on the population densities of $P$. loosi (Choshali et al., 2015). It has been also reported that $P$. loosi populations are more abundant in tea fields above $1219 \mathrm{~m}$ altitude (Hutchinson and Vythilingam, 1963). However, our findings experienced a lower $P$. loosi population in location PL2 with a higher altitude than $1219 \mathrm{~m}$. This may be probably due to the lowest soil moisture content as recorded in the present study (Table 2).

\section{Correlation between Soil Moisture Content and P. loosi Population Densities}

Soil moisture plays a major role in soil biota inclusive of parasitic nematodes, saprophytic nematodes and their biological control agents. In tea lands, soil moisture levels are influenced by rainfall, soil type and the cultural practices adopted. Data on P. loosi in soil and roots of the study locations are described with varying levels of soil moisture.

\section{Correlation between Soil Moisture Content and $P$. loosi Population Densities in Soil}

The Fig. 3 presents the relationship between soil moisture content and P. loosi population levels in soil. 


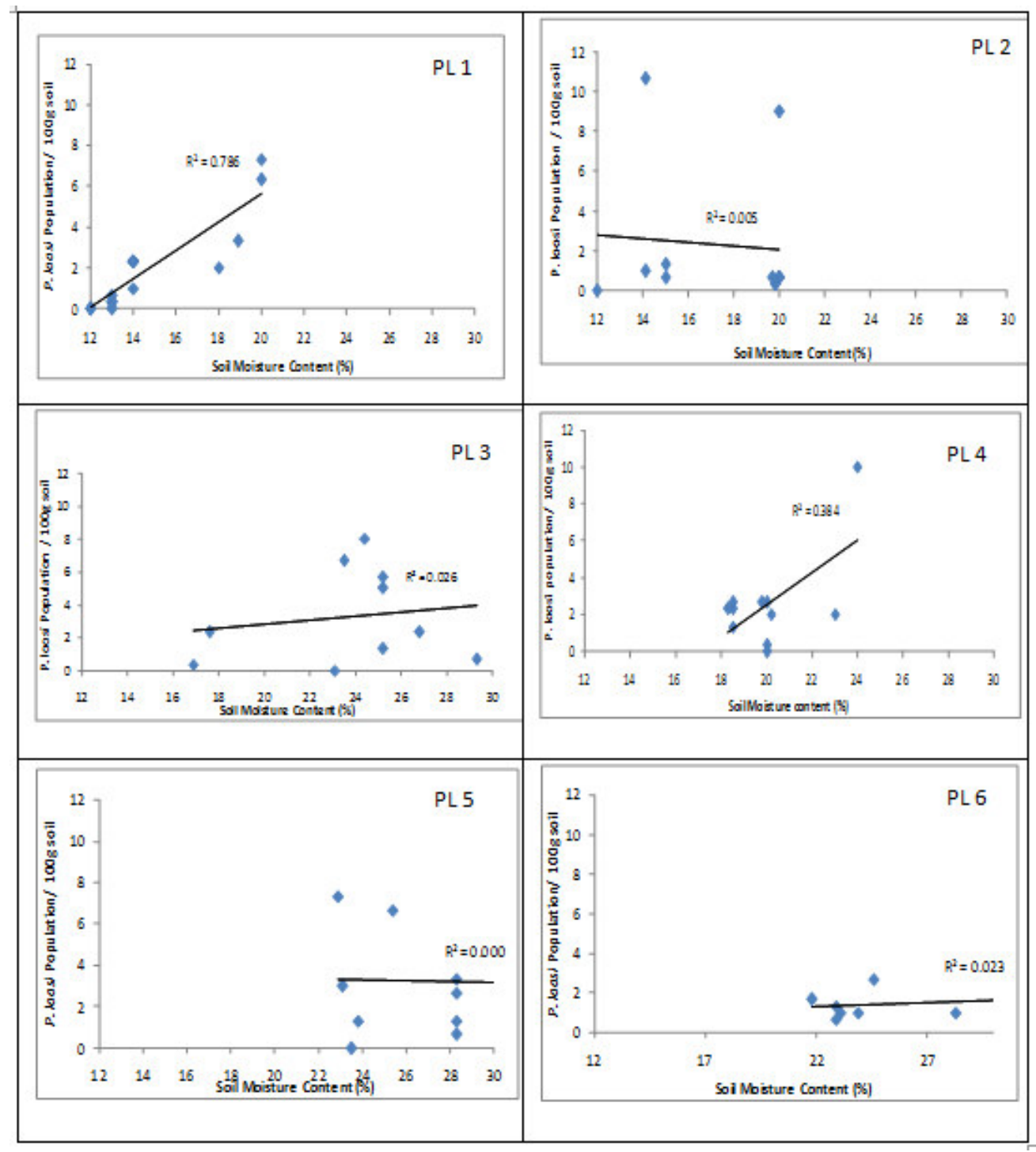

Fig 3. Correlation between Soil Moisture and $P$. loosi populations in soil in six locations (PL1 -PL6)

All $P$. loosi populations were positively correlated with the soil moisture content except in locations PL2 and PL5 (Fig. 3). The negative relationships at PL2 and PL5 $\left(R^{2}=-0.005\right.$ and 0.000 respectively) locations could be due to the extremely lowest and highest moisture contents in the respective soils as shown in Table 2, which are detrimental to the survival of nematodes. It also suggests the poor survival and adaptation mechanisms of the isolates of $P$. loosi at those locations to extreme soil moisture contents. In depth studies to understand responses of different $P$. loosi populations to varying soil moisture levels and search for specific nematode management practices to such nematode isolates are warranted. 
a)

Correlation between Soil Moisture Content and P. loosi Population Densities in Roots

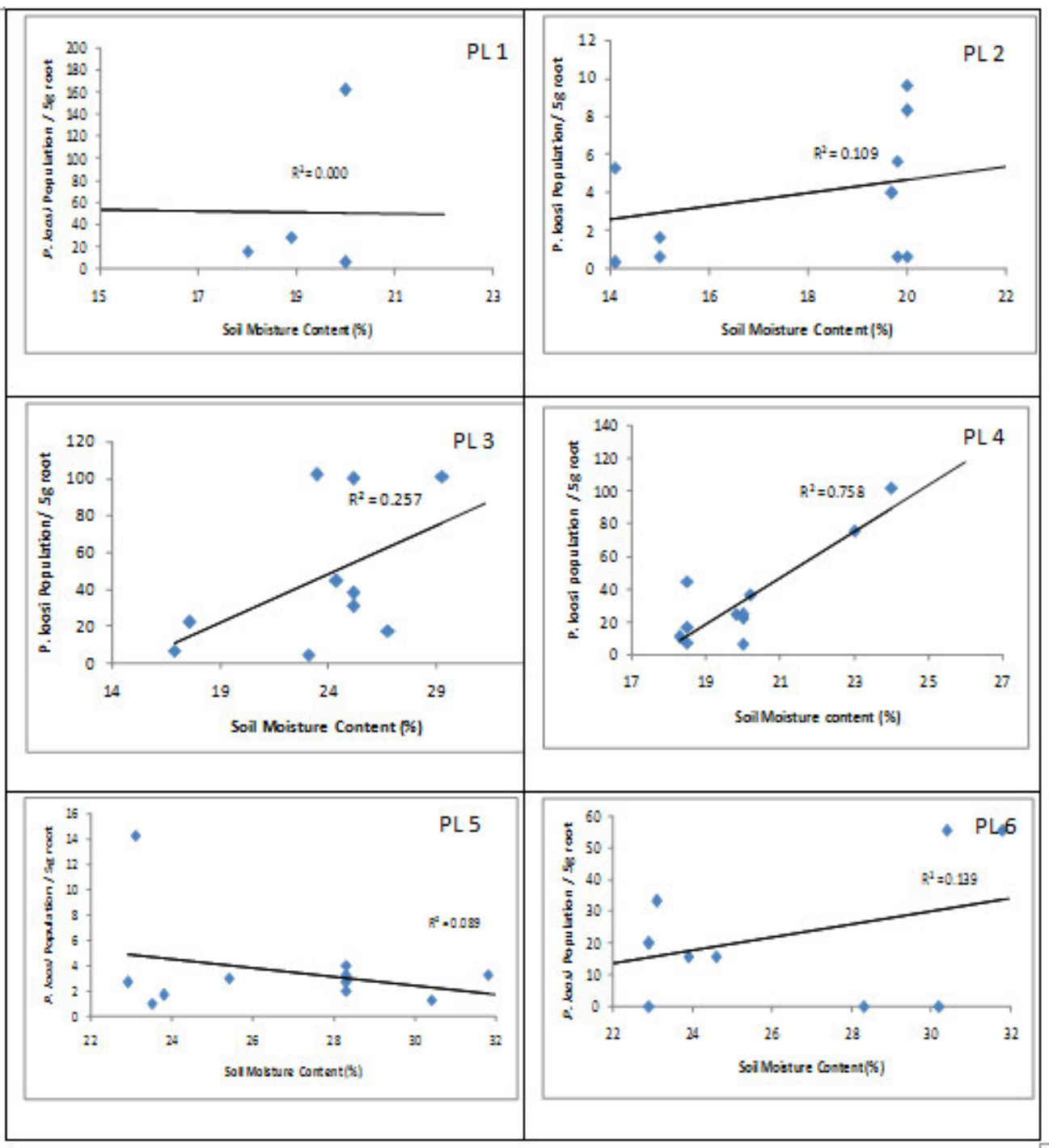

Fig 4. Correlation between Soil Moisture content and $P$. loosi populations in roots in locations PL1 -PL 6

P. loosi is a migratory endoparasite and the root population density depends on changing soil environments. Therefore, root nematode population becomes increased when the soil conditions are unfavorable. Our results support the initial understanding of positive relationship with higher soil moisture content with $P$. loosi populations in roots in locations except PL1 and PL5 (Fig. 4). This confirms that population increase of $P$. loosi depends not only on soil moisture but also other factors as well. The type of soil and its management may have interfered with the magnitude of changes in soil environment which need further investigations under controlled environmental conditions. 
In tea, the information on impacts of weather factors on tea pests are scares besides the responses of tea growth and productivity. Erratic incidences and significant fluctuations of nematode species in different tea growing regions were reported in the recent past. Therefore novel approaches of location specific nematode management strategies need to be introduced. Therefore, further attempts were made to study the effect of changing rainfall, soil temperature and soil moisture on population dynamics of $P$. loosi in tea lands in six locations covering agro ecological regions and elevations and under controlled environments.

\section{CONCLUSIONS}

Survival rates and pathogenicity of plant parasitic nematodes are sensitive to changing rainfall and soil temperature. However, in tea, the information on impacts of climate change on tea pests are scares besides the responses on growth and productivity are evident. Erratic incidences and significant fluctuations of nematode species in different tea growing regions were reported in the recent past warranting novel approaches of location specific nematode management strategies. Therefore, further attempts were made to determine the effects of changing rainfall and soil temperature on population dynamics of $P$. loosi in tea lands in six locations covering agro ecological regions and elevations and under controlled environments.

In comparison with past records, the results revealed a wide variation in rainfall, soil temperature and soil moisture in favor of $P$. loosi in the different study locations. As soil temperature is the most determining factor for $P$. loosi incidence in tea, the changes in soil temperature were seen significant in majority of the study locations with a rising trend from 19.3-31. $2^{0} \mathrm{C}$; extreme soil temperature ranges were also seen where the optimal range for $P$. loosi is $18-24^{\circ} \mathrm{C}$. As the nematode incidence above economic threshold levels and symptomologies were continued, new adaptations, emergence of new races and / or isolates of $P$. loosi etc. are therefore possible. In general, a negative correlation between soil temperature and $P$. loosi population in soil was evident in locations except in PL $1\left(\mathrm{R}^{2}=\right.$ $0.006)$ and PL $4\left(\mathrm{R}^{2}=0.173\right)$. Results did not reveal any strong adaptations of $P$. loosi populations to the higher temperatures and continued to behave as a subtropical nematode species. $P$. loosi densities in soil varied with the rainfall pattern and the results corroborated findings of Sivapalan (1972) and evidences in field.

These results also validate potentials of wide spread of this species and dominate in all tea growing regions as well as presence as concomitant occurrence with other nematode species such as $R$. similis requiring higher soil temperatures. In contrast, $R$. similis has been sensitive with such climate change scenarios as its occurrence has been minimized in general and in certain locations previously known as critical, has been totally replaced by $P$. loosi (Mohotti, 2009). Hence, $P$. loosi showed its virulence as a dominating nematode species with potential survival mechanisms and adaptations to get established and developed even under extreme weather conditions. This warrants further understanding as well as search for navel management practices.

All $P$. loosi populations were positively correlated with the soil moisture content except in locations PL2 and PL5. The poor relationship $\left(\mathrm{R}^{2}=-0.005\right.$ and 0.000 respectively) in such locations revealed that $P$. loosi populations seem comparatively less sensitive with possible adaptations and enhanced survival mechanisms. In depth studies to understand responses of different $P$. loosi populations to varying soil moisture levels are warranted and also to search for specific nematode management practices. 
The results support the initial understanding of soil moisture content with $P$. loosi populations in roots with positive correlations except in locations PL1 and PL5. The type of soil and its management etc. may interfere with the magnitude of changes in soil environment which need further investigations under controlled environmental conditions.

According to the past experiences, $P$. loosi is widely distributed in tea plantations in the elevation range $750-1800 \mathrm{~m}$ with the greatest damage in the range of $1200-1700 \mathrm{~m}$ and hence called as the 'Up country nematode species'. However, our results revealed that $P$. loosi could exist in locations irrespective of elevation ranges and could cause damage to tea.

Research evidence on emergence and incidence of $P$. loosi and decrease or disappearance of $R$. similis densities in tea lands warrants adequate attention for mitigation strategies and location specific nematode management methods. Further, the results highlighted potentials of harnessing nematodes as a sound biological indicator in climate change impacts in agriculture.

\section{REFERENCES}

Choshali, A.H., Seraji, A., Rezaee, S., Shirinfekr, A., and Mirghasemi S.N. (2015). The effects of soil organic matter content and soil texture on the population number of Pratylenchus loosi, in tea plantation of Iran. International Journal of Agronomy and Agricultural Research. 6(2), 54 - 61.

Gnanapragasam, N.C. and Mohotti, K.M. (2005). Nematode Parasites of Tea. In: Luc, M., Sikora, R.A. and Bridge, J. (ed). Plant Parasitic Nematodes in Sub Tropical and Tropical Agriculture. pp. 581 - 593.

Gnanapragasam, N.C. and Mohotti, K.M. (2008). Management of nematode pests. In: Zoysa, A.K.N. Hand Book on Tea, eds. Tea Research Institute of Sri Lanka, Talawakelle. pp. 241 254.

Gnanapragasam, N.C. (1994). Effect of environment on population dynamics of plant parasitic nematodes and consequent pathogenicity to tea. Tea Bulletin. 14, 18 - 24.

Hahn, M.L., Burrows, P.R., Gnanapragasam, N.C., Bridge, J., Vines, N.J. and Wright. D.J. (1994). Molecular diversity amongst Radopholus similis populations from Sri Lanka detected by RAPD analysis. Fundamental Applied Nematology. 17(3), 275 - 281.

Hutchinson, M.T. and Vythilingam, M.K. (1963). Distribution of plant parasitic nematodes in the soils in Ceylon, with particular reference to altitude. Tea Quarterly. 34, 119 - 126.

Liliane R., Anders, M., Inger, K.S., and Sven, J. (1999). Simulated climate change affecting microorganisms, nematode density and biodiversity in subarctic soils. Plant and Soil. 212(1), $63-73$.

Mohotti K.M., (1998). Non-chemical approaches for the management of the root lesion nematode, Pratylenchus loosi Loof, 1960 in tea (Camellia sinensis (L) O. Kuntze) with special reference to use of endospore-forming bacterium, Pasteuria penetrans. $\mathrm{PhD}$ Thesis, Department of Agriculture, University of Reading, UK. pp. 289. 
Mohotti, K.M. (2009). Marked shift in damage caused by parasitic nematode species in tea with long term climate change in Sri Lanka. Climate change and its impacts on Agriculture, Forestry and Water. Abstracts of the $1^{\text {st }}$ National conference, Kandy, Sri Lanka. pp. 30 - 31 .

Sivapalan, P. (1972). Nematode Pests of Tea. In Webster, J.M. [Ed.]: Economic Nematology. New York and London. Academic Press. pp. 285 - 310.

Sivapalan, P. and Gnanapragasam, N.C. (1975). The effect of soil temperature and infestation by Pratylenchus loosi on the growth and nutrient status of a susceptible and tolerant variety of young tea (Camellia sinensis L.). Tea Quarterly. Tea Research Institute, Sri Lanka. 45, 29 - 35.

Somashekar, N., Prasad, J.S., Ganguly, A.K. (2010). Impact of climate change on soil nematodes - Implications for sustainable Agriculture. Indian Journal of Nematology. 40(2), $125-134$.

Southey, J.F. (1986). Laboratory methods for work with plant and soil nematodes. Technical Bulletin. No. 2. Ministry of Agriculture, Fisheries and Food. United Kingdom. pp. 202.

Wijeratne, M.A. and Chandrapala, L. (2013). Analysis of Rainfall and Temperature in Tea Growing Agro-Ecological Regions and Assessment of Vulnerability of Sri Lanka Climate Change. Sri Lanka Journal of Tea Science. Tea Research Institute, Sri Lanka. 78, 42 - 59. 